\title{
Desempenho de cultivares de tomate italiano de crescimento determinado em cultivo protegido sob altas temperaturas
}

\author{
Daiane Andréia TRENTO1*, Darley Tiago ANTUNES ${ }^{1}$, Flávio FERNANDES JÚNIOR ${ }^{2}$, \\ Márcio Roggia ZANUZO ${ }^{3}$, Rivanildo DALLACORT ${ }^{4}$, Santino SEABRA JÚNIOR ${ }^{1}$ \\ ${ }^{1}$ Universidade do Estado de Mato Grosso, Nova Mutum, MT, Brasil. \\ ${ }^{2}$ Empresa Brasileira de Pesquisa Agropecuária, Sinop, MT, Brasil. \\ ${ }^{3}$ niversidade Federal de Mato Grosso, Sinop, MT, Brasil. \\ ${ }^{4}$ Universidade do Estado de Mato Grosso, Tangará da Serra, MT, Brasil. \\ *E-mail: daiatrento@gmail.com \\ (Orcid: 0000-0002-9573-7931; 0000-0002-3295-5165; 0000-0001-8239-6894; 0000-0002-2957-2198; \\ 0000-0002-7634-8973; 0000-0002-4986-7778)
}

\begin{abstract}
Recebido em 11/08/2020; Aceito em 31/08/2021; Publicado em 24/09/2021.
RESUMO: O objetivo desse trabalho foi avaliar a produção, a qualidade e tempo de prateleira de cultivares de tomate tipo italiano de crescimento determinado, produzidos sob ambiente protegido em condições de altas temperaturas. O cultivo foi realizado em Nova Mutum - MT, foram avaliados cinco cultivares: Fascínio (Feltrin sementes), Hy Color (Horticeres), Santa Adélia (TopSeed), SM-16 (Seminis) e Supera F1 (TopSeed), dispostos em blocos casualizados, com quatro repetições. As plantas foram conduzidas em "meia estaca" e não foram podadas. Os parâmetros avaliados foram relativos a produção, a qualidade dos frutos, tempo de prateleira e qualidade no pós-colheita. A cultivar Fascínio apresentou produtividade de 186,1 t ha-1, maior massa média de frutos $(144,3 \mathrm{~g})$, maior calibre de fruto, $(60,7 \mathrm{~mm})$, e menor perda de massa no pós-colheita $(6,23 \%)$. Os melhores resultados de sólidos solúveis totais dos frutos que completaram a maturação na planta foram obtidos das cultivares Santa Adélia (4,3), Fascínio (4,27) e Hy Color (4,21), e dos frutos colhidos no estádio verdemaduro obteve destaque a cultivar Santa Adélia $(5,85)$, e os frutos que ficaram em temperatura ambiente obtiveram maior média de sólidos solúveis totais $(5,55)$.
\end{abstract}

Palavras-chave: termotolerância; Lycopersicum esculentum Mill; produtividade; pós colheita; ambiente protegido.

\section{The performance of determinate growth italian tomato cultivars in protected cropping under high temperatures}

\begin{abstract}
This study aimed to evaluate the production, quality and shelf time of determinate growth Italian tomato cultivars from a protected environment under high temperature conditions. The cultivation was conducted in Nova Mutum, state of Mato Grosso, Brazil. Five cultivars were evaluated: 'Fascínio' (Feltrin Sementes), 'Hy Color' (Horticeres), 'Santa Adélia' (TopSeed), 'SM-16' (Seminis) and 'Supera F1' (TopSeed), disposed in randomized blocks with four repetitions. The plants were managed into the "meia estaca" tutoring method and were not pruned. The parameters evaluated were related to the production, quality of fruits, shelf time and postharvest quality. The 'Fascínio' cultivar presented productivity of $186.1 \mathrm{t} \mathrm{ha}^{-1}$, the largest average fruit weight $(144.3 \mathrm{~g})$, the largest fruit gauge $(60.7 \mathrm{~mm})$ and the smallest postharvest weight loss $(6.23 \%)$. The total soluble solids best results of fruits that have matured in the plant were obtained from the 'Santa Adélia' (4.3), 'Fascínio' (4.27) e 'Hy Color' (4.21) cultivars. Among the fruits harvested at the mature-green stage, the 'Santa Adélia' (5.85) cultivar stood out. The fruits that stayed at room temperature obtained the largest total soluble solids average (5.55).
\end{abstract}

Keywords: thermotolerance; Lycopersicum esculentum Mill; productivity; postharvest; protected environment.

\section{INTRODUÇÃO}

O tomate (Solanum lycopersicum Mill.), é uma das hortaliças mais cultivadas e consumidas no mundo, apresentando elevada importância econômica, sendo responsável pela geração de empregos nos setores de produção e por grande parte do mercado de sementes de hortaliças (ANUÁRIO ABRASEM, 2016). O Brasil ocupa o nono lugar na produção mundial de tomate, com destaque aos estados de Goiás, São Paulo e Minas Gerais (FAOSTAT, 2018). No estado do Mato Grosso a produção de tomate em 2016 ocupou uma área de 236 hectares, produzindo um total de 5.890 toneladas
(AGRIANUAL, 2016), insuficiente para atender a demanda interna.

Altas temperaturas e pluviosidade, comuns em regiões tropicais, são fatores que comprometem a produtividade de culturas como o tomate (LI et al., 2013), sendo necessário a utilização de tecnologias como o cultivo em ambiente protegido e a identificação de cultivares termotolerantes.

$\mathrm{O}$ ambiente protegido para cultivo do tomateiro age como barreira física contra o ataque de insetos-praga e protege as plantas da precipitação (BAZGAOU et al., 2018) 
e ainda proporciona ganhos na produção de 4 a $15 \%$ quando comparado ao campo aberto (MARTINS, 1992).

Por isso a técnica vem sendo incentivada visando melhorar a qualidade dos frutos e aumento da produtividade na entressafra, diminuindo a sazonalidade da oferta e diminuição do uso de agrotóxicos (BAZGAOU et al., 2018).

O tomate de hábito de crescimento determinado destaca-se pela rusticidade e dispensa tratos culturais como podas, raleio de frutos e tutoramento. Por apresentar essas características, resulta no menor aporte de mão de obra, torna-se atrativo também ao produtor que visa o mercado de mesa "in natura", desde que atenda as características de qualidade de fruto desejadas (ALVARENGA, 2013).

Considerando as particularidades da cultura do tomateiro torna-se necessária uma comparação entre diferentes cultivares dentro das mesmas condições edafoclimáticas, buscando adaptabilidade, alta produção, tipo de fruto adequado ao consumo "in natura", com boa qualidade e aparência externa, com reduzidos tratos culturais, além de resistência ao transporte e tempo de prateleira.

As frutas e hortaliças contém um elevado teor de umidade e suas atividades metabólicas não cessam após a colheita, tornando-as assim altamente perecíveis, e as condições climáticas em regiões tropicais favorecem a rápida deterioração após a colheita. Uma alternativa para aumentar o tempo de prateleira de frutos frescos é a utilização de ambientes refrigerados. A refrigeração baseia-se na inibição total ou parcial, dos principais agentes: ação química, enzimática e o crescimento microbiano, responsáveis pela deterioração dos alimentos. É considerado um método temporário de conservação, geralmente dias ou semanas, porque as atividades dos agentes não são inibidas, apenas desaceleradas (VASCONCELOS; FILHO, 2016), mas devese atentar para a temperatura empregada, pois podem causar alterações na maturação, aspecto visual e coloração (STEFFENS, 2007).

Neste contexto, o objetivo desse trabalho foi avaliar a produção, a qualidade e tempo de prateleira de cultivares de tomate tipo italiano de crescimento determinado, produzidos sob ambiente protegido em condições de altas temperaturas.

\section{MATERIAL E MÉTODOS}

O experimento foi realizado na área experimental do Campus Universitário de Nova Mutum - UNEMAT, que está localizado na latitude sul $13^{\circ} 05^{\prime} 04^{\prime \prime}$ e longitude oeste $56^{\circ} 05^{\prime}$ 16". O solo é Latossolo Vermelho Amarelo distrófico. O clima é do tipo Aw (Koppen), tropical, com chuvas concentradas no verão (outubro a abril). A precipitação média anual é de $1900 \mathrm{~mm}$ e a temperatura média é de $26^{\circ} \mathrm{C}$ (NOGUEIRA et al., 2010).

As mudas foram produzidas no viveiro da área experimental de horticultura da UMEMAT, sob ambiente protegido coberto com filme transparente de polietileno de baixa densidade, em bandejas de poliestireno expandido, modelo 128/6 (formato de pirâmide invertida), utilizando para preenchimento o substrato comercial Vivato ${ }^{\circledR}$. O transplantio foi realizado 28 dias após a semeadura.

O cultivo do tomateiro foi realizado em ambiente protegido é do tipo arco coberto com filme agrícola de 150 micras e pé direto de $3 \mathrm{~m}$, com dimensão de $7 \times 21 \mathrm{~m}$. As laterais foram fechadas com tela de sombreamento $50 \%$ de cor preta. O delineamento experimental utilizado foi o de blocos casualizados, com quatro repetições, sendo cada parcela composta por $7,14 \mathrm{~m}^{2}$ e 16 plantas por parcela, considerando a parcela útil às seis plantas centrais.

Os tratamentos consistiram em cinco cultivares de tomate de hábito determinado, sendo: Fascínio (Feltrin sementes), Hy Color (Horticeres), Santa Adélia (TopSeed), SM-16 (Seminis) e Supera F1 (TopSeed). O tutoramento utilizado foi do tipo "meia estaca", onde foram fixadas estacas de $1,4 \mathrm{~m}$ de altura a cada 2 metros, e foram passados fitilhos dispostos horizontalmente a cada 30 centímetros de altura, de forma a abraçarem as plantas, mantendo-as eretas e o espaçamento foi de $0,5 \mathrm{~m}$ entre plantas e $0,8 \mathrm{~m}$ entre linhas, com irrigação do tipo gotejamento na base de cada planta. (Figuras 3 e 4). A fertilidade do solo foi corrigida com base na análise química do solo segundo recomendação de Alvarenga (2013) e Silva et al. (2007), sendo aplicado 681,8 $\mathrm{Kg} \mathrm{ha}^{-1}$ de uréia $(44 \% \mathrm{~N})$, distribuídos em $10 \%$ no plantio e os restante em coberturas fracionadas, $10 \%$ entre os 40 e 55 DAS, $20 \%$ entre os 70 e 85 dias DAS, $15 \%$ entre os 100 e 115 DAS, $5.550 \mathrm{Kg} \mathrm{ha}^{-1}$ de superfosfato simples $\left(18 \% \mathrm{P}_{2} \mathrm{O}_{5}\right)$ distribuído em $70 \%$ no plantio e $30 \%$ em cobertura aos 40 DAS, e $1.034,4 \mathrm{Kg} \mathrm{ha} \mathrm{h}^{-1}$ de cloreto de potássio $\left(58 \% \mathrm{~K}_{2} \mathrm{O}\right)$, distribuído em $10 \%$ no plantio, e em cobertura foi aplicado $15 \%$ aos 40 e 55 DAS, $20 \%$ aos 70 e 85 DAS, $15 \%$ aos 100 DAS e $5 \%$ aos 115 DAS.

Os dados de temperatura foram monitorados diariamente às 13 horas, utilizando termômetro digital marca HighMed, instalado a $1,1 \mathrm{~m}$ do chão, na parte central da casa de vegetação.

Para os parâmetros de produção, os frutos foram colhidos no estágio de maturação vermelho maduro, onde mais de $90 \%$ da superfície do fruto se encontra na coloração vermelho-intensa. Foram avaliados todos os frutos colhidos durante o ciclo das plantas úteis, sendo avaliados a produção total $\left(\mathrm{T} \mathrm{ha}^{-1}\right)$, número de frutos por planta (unidade) e massa de fruto $(\mathrm{g})$, calibre, grupo de acordo com o formato do fruto, espessura do pericarpo ( $\mathrm{mm})$ e sólidos solúveis totais $\left({ }^{\circ}\right.$ Brix).

O calibre do tomate é determinado pelo diâmetro equatorial do fruto, sendo assim separado em 8 classes: 0 para diâmetro menor que $40 \mathrm{~mm}$; 40 para diâmetro maior ou igual que $40 \mathrm{~mm}$ até $50 \mathrm{~mm}$; 50 para diâmetro igual ou maior que $50 \mathrm{~mm}$ até $60 \mathrm{~mm}$; 60 para diâmetro igual ou maior que 60 $\mathrm{mm}$ até $70 \mathrm{~mm} ; 70$ para diâmetro igual ou maior que $70 \mathrm{~mm}$ até $80 \mathrm{~mm} ; 80$ para diâmetro maior ou igual a $80 \mathrm{~mm}$ até 90 $\mathrm{mm}$; 90 para diâmetro maior ou igual a $90 \mathrm{~mm}$ até $100 \mathrm{~mm}$; 100 para diâmetro maior que $100 \mathrm{~mm}$ (CEAGESP, 2006).

Para a mensuração do teor de sólidos solúveis totais (SST), em ${ }^{\circ}$ Brix foi cortado $1 / 4$ dos frutos colhidos em cada planta e processado com a utilização do mixer, visando a homogeneização da amostra. Posteriormente, o suco era peneirado em filtro de papel qualitativo, com gramatura de $80 \mathrm{~g} / \mathrm{m}^{2}$, e porosidade de três micras. Com este era realizada a leitura do SST em refratômetro manual digital modelo ITREFD 65, com compensação automática de temperatura.

Para o teste de prateleira, foram selecionados 20 frutos de cada cultivar, colhidos no estágio de maturação verdemaduro, no qual o fruto já está maduro fisiologicamente, mais ainda apresenta coloração totalmente verde, selecionados homogeneamente, selecionados quanto à uniformidade de tamanho e coloração e sem defeitos aparentes. Os frutos foram dispostos em dois ambientes (prateleira em temperatura ambiente e geladeira), com três repetições.

No laboratório, os frutos foram higienizados e secos, posteriormente divididos nos dois ambientes, sendo que no 
primeiro os frutos foram dispostos sobre uma bancada de mármore, em temperatura ambiente, em uma sala de $72 \mathrm{~m}^{2}$, com temperatura média de $27,2^{\circ} \mathrm{C}$ e umidade relativa de $70 \%$, e outra parte dos frutos foram colocados em refrigerador Eletrolux, modelo DF 42, com capacidade de 382 litros, com temperatura média de $6,7^{\circ} \mathrm{C}$ e umidade relativa de $10 \%$. Em ambos os ambientes os frutos foram distribuídos sem qualquer embalagem.

Foi registrada a perda de massa por semana, durante cinco semanas, onde a perda de massa foi analisada pela relação da diferença entre a massa inicial e o final e apresentada como porcentagem da massa inicial, a qual foi realizada periodicamente, em intervalos de sete dias, iniciando-se no dia da colheita e finalizando após 28 dias de armazenamento à temperatura ambiente.

O acompanhamento do grau de maturação foi realizado de acordo com a classificação de subgrupo (Brasil,1995), onde foram atribuídas notas de 1 a 5 em função do estágio de maturação, sendo:

1 - verde maduro: quando se evidencia o início de amarelecimento na região apical do fruto;

2 - pintado (de vez): quando as cores amarelo, rosa ou vermelho encontram-se entre 10 (dez) e 30 (trinta) por cento da superfície do fruto;

3 - rosado: quando $30 \%$ a $60 \%$ do fruto encontra-se vermelho;

4 - vermelho: quando o fruto apresenta entre 60 e $90 \%$ da sua superfície vermelha;

5 -vermelho maduro: quando mais de $90 \%$ da superfície do fruto encontra-se vermelha intensa.

Para análise de qualidade, foi realizada a mensuração de sólidos solúveis totais ( ${ }^{\circ}$ Brix) em amostras no momento da colheita, e repetida no $28^{\circ}$ dia após armazenamento.

Os dados obtidos foram submetidos à análise de variância e as médias comparadas no teste de Scott-knott $(\mathrm{P}<0,05)$, utilizando o programa (software) Assistat Versão 7.7 Beta (PT) (SILVA; AZEVEDO, 2002).

\section{RESULTADOS}

No período do experimento, a média máxima de temperatura ficou em $35,7^{\circ} \mathrm{C}$, e das mínimas $20,0^{\circ} \mathrm{C}$, e a média geral $27,4^{\circ} \mathrm{C}$, sendo que as médias das máximas e das mínimas registradas entre o início da floração e o início da colheita foi de $33,3^{\circ} \mathrm{C}$ e $19,2^{\circ} \mathrm{C}$, respectivamente. Houve grande variação entre as temperaturas noturnas e diurnas, ocasionando uma amplitude térmica diária com média de variação de $15,7^{\circ} \mathrm{C}$.

A cultivar Fascínio apresentou maior produtividade (Tabela 1), resultado esse bastante superior às demais cultivares, sendo que essas não apresentaram diferença quanto a produção. Com relação ao número médio de frutos por planta, pode-se dividir as cultivares em três grupos, sendo a cultivar Hy Color a que obteve a maior quantidade de fruto, a 'Fascínio' que obteve um desempenho intermediário, e as cultivares SM-16, Supera F1 e Santa Adélia que apresentaram menor número de frutos.

A cultivar Fascínio se destacou com maior calibre de fruto, sendo considerada classe 60, seguida das cultivares SM16, Santa Adélia e Supera F1, as quais não diferiram estatisticamente entre si e consideradas dentro da classe 50 , e com menor diâmetro encontrado ficou a cultivar Hy Color de classe 40
A cultivar Fascínio apresentou maior massa unitária de frutos, seguida pelas cultivares SM-16 e Supera F, e a 'Hy Color' apresentou a menor massa. Com relação ao comprimento do tomate (Tabela 2), se destacaram as cultivares Fascínio, SM-16 e Supera F1, seguida da cultivar Santa Adélia, e com menor comprimento ficou a Hy Color.

Tabela 1. Médias de produtividade $\left(\mathrm{t} \mathrm{ha}^{-1}\right)$, massa de frutos $(\mathrm{g}) \mathrm{e}$ quantidade de frutos por planta (unidade) entre cultivares de tomate de hábito determinado, produzidos em ambiente protegido.

Tabela 1. Yield averages ( $\left.\mathrm{tha}^{-1}\right)$, number of fruits per plant (unit) and unit weight of fruits (g) among determined tomato habit cultivars, produced in a protected environment

\begin{tabular}{lccc}
\hline Cultivares & Prod. $\left(\mathrm{t} \mathrm{ha}^{-1}\right)$ & $\begin{array}{c}\text { Frutos por } \\
\text { planta } \\
\text { (unidade) }\end{array}$ & $\begin{array}{c}\text { Massa } \\
\text { unitária de } \\
\text { frutos }(\mathrm{g})\end{array}$ \\
\hline Fascínio & $186,1 \mathrm{a}$ & $52,1 \mathrm{~b}$ & $144,3 \mathrm{a}$ \\
SM-16 & $139,2 \mathrm{~b}$ & $45,4 \mathrm{c}$ & $115,1 \mathrm{~b}$ \\
Supera F1 & $120,4 \mathrm{~b}$ & $44,5 \mathrm{c}$ & $111,1 \mathrm{~b}$ \\
Santa Adélia & $107,7 \mathrm{~b}$ & $46,2 \mathrm{c}$ & $93,5 \mathrm{c}$ \\
Hy Color & $125,1 \mathrm{~b}$ & $72,4 \mathrm{a}$ & $69,1 \mathrm{~d}$ \\
\hline CV $(\%)$ & 10,5 & 5,7 & 9,2 \\
\hline
\end{tabular}

Médias seguidas de mesma letra nas colunas não diferem entre si pelo teste de Scott-knott a $5 \%$ de probabilidade.

Means followed by the same letter in the column do not differ significantly by Scott-knott with $\mathrm{p}<(0,05)$.

Tabela 2. Médias de comprimento do fruto - CF ( $\mathrm{mm}$ ), diâmetro do fruto - DF (mm), relação diâmetro comprimento do fruto - Relação $\mathrm{C} / \mathrm{D}$ e espessura do pericarpo - EP ( $\mathrm{mm}$ ) entre cultivares de tomate de hábito determinado, produzidos em ambiente protegido.

Tabela 2. Means of fruit shape - CF (mm), fruit diameter - DF (mm), ratio - C/D, pericarp thickness - EP $(\mathrm{mm})$ among determined tomato habit cultivars, produced in a protected environment.

\begin{tabular}{lcccc}
\hline Cultivares & CF $(\mathrm{mm})$ & $\begin{array}{c}\text { DF } \\
(\mathrm{mm})\end{array}$ & $\begin{array}{c}\text { Relação } \\
\text { C/D }\end{array}$ & $\begin{array}{c}\text { EP } \\
(\mathrm{mm})\end{array}$ \\
\hline Fascínio & $70,4 \mathrm{a}$ & $60,7 \mathrm{a}$ & $1,16 \mathrm{~b}$ & $10,4 \mathrm{a}$ \\
SM-16 & $68,3 \mathrm{a}$ & $55,3 \mathrm{~b}$ & $1,23 \mathrm{a}$ & $10,1 \mathrm{a}$ \\
Supera F1 & $68,2 \mathrm{a}$ & $53,8 \mathrm{~b}$ & $1,26 \mathrm{a}$ & $9,6 \mathrm{a}$ \\
Sta Adélia & $65,0 \mathrm{~b}$ & $51,8 \mathrm{~b}$ & $1,25 \mathrm{a}$ & $9,4 \mathrm{a}$ \\
Hy Color & $55,9 \mathrm{c}$ & $48,3 \mathrm{c}$ & $1,16 \mathrm{~b}$ & $7,2 \mathrm{~b}$ \\
\hline CV $(\%)$ & 3,50 & 3,73 & 1,6 & 9,29 \\
\hline
\end{tabular}

Médias seguidas de mesma letra nas colunas não diferem entre si pelo teste de Scott-knott a 5\% de probabilidade.

Means followed by the same letter in the column do not differ significantly by Scott-knott with $\mathrm{p}<(0,05)$.

Avaliando a espessura do pericarpo (Tabela 2), não houve diferença entre as cultivares Fascínio, SM-16, Santa Adélia e Supera $\mathrm{F} 1$, as quais obtiveram médias entre $10,4 \mathrm{~mm}$ e 9,4 $\mathrm{mm}$, e a cultivar Hy color obteve menor espessura da parede.

No pós-colheita, a cultivar Fascínio obteve as menores médias de perda de massa, e entre ambientes, a geladeira propiciou menores médias após os 28 dias do experimento (Tabela 3).

Quanto à maturação dos frutos colhidos no ponto verdemadura, os tomates dispostos na geladeira não alcançaram o ponto de maturação vermelho maduro após os 28 dias da colheita, obtendo nota 3 (rosado), e os frutos mantidos em temperatura ambiente completaram a maturação vermelho maduro (Tabela 4).

Em relação aos sólidos solúveis totais dos frutos no estádio verde maduro, as cultivares Fascínio, SM-16, Santa Adélia, e Hy Color não se diferiram estatisticamente, e a cultivar Supera F1 obteve a menor média (Tabela 5). Os maiores teores de sólidos solúveis totais dos frutos que completaram sua maturação na planta foram obtidos nas cultivares Santa Adélia, Fascínio e Hy Color. As cultivares 
SM-16 e Supera F1 compuseram o grupo de menor teor de sólidos solúveis totais.

Tabela 3. Percentual de perda de massa no pós-colheita de tomates colhidos no ponto verde maduro, dispostos em dois ambientes com diferentes temperaturas.

Tabela 3. Postharvest weight loss of tomatoes (\%) harvested at the ripe green index, in two environments with different temperatures.

\begin{tabular}{lcccc}
\hline & 7 Dias & 14 Dias & 21 Dias & 28 Dias \\
\hline Cultivares & & & & \\
\hline Fascínio & $3,20 \mathrm{a}$ & $5,17 \mathrm{a}$ & $6,23 \mathrm{a}$ & $7,32 \mathrm{a}$ \\
SM-16 & $5,62 \mathrm{~b}$ & $9,27 \mathrm{~b}$ & $11,46 \mathrm{~b}$ & $12,53 \mathrm{~b}$ \\
Sta Adélia & $5,23 \mathrm{~b}$ & $8,90 \mathrm{~b}$ & $11,68 \mathrm{~b}$ & $13,70 \mathrm{~b}$ \\
Supera F1 & $5,69 \mathrm{~b}$ & $9,16 \mathrm{~b}$ & $11,90 \mathrm{~b}$ & $13,47 \mathrm{~b}$ \\
Hy Color & $4,93 \mathrm{~b}$ & $8,90 \mathrm{~b}$ & $11,92 \mathrm{~b}$ & $14,28 \mathrm{~b}$ \\
\hline Ambientes & & & & \\
\hline Geladeira & $4,56 \mathrm{a}$ & $7,80 \mathrm{a}$ & $9,98 \mathrm{a}$ & $11,32 \mathrm{a}$ \\
$\mathrm{T}^{\circ}$ Amb. & $5,31 \mathrm{~b}$ & $8,77 \mathrm{~b}$ & $11,30 \mathrm{a}$ & $13,19 \mathrm{~b}$ \\
\hline CV $(\%)$ & 18,75 & 18,07 & 17,20 & 16,94 \\
\hline
\end{tabular}

Médias seguidas de mesma letra nas colunas não diferem entre si pelo teste de Scott-knott a 5\% de probabilidade.

Means followed by the same letter in the column do not differ significantly by Scott-knott with $\mathrm{p}<(0,05)$.

Tabela 4. Classificação do grau de maturação do tomate colhido no ponto I (verde-maduro) dispostos em temperatura ambiente e geladeira, durante quatro semanas de pós-colheita.

Tabela 4. Classification of ripening tomatoes index harvested at point I (ripe-green) stored at room temperature and in the cooling room, during four post-harvest weeks.

\begin{tabular}{|c|c|c|c|c|}
\hline & 7 Dias & 14 Dias & 21 Dias & 28 Dias \\
\hline \multicolumn{5}{|l|}{ Cultivares } \\
\hline Fascínio & $1,83 \mathrm{a}$ & $3,16 \mathrm{a}$ & $4,00 \mathrm{a}$ & $4,16 \mathrm{a}$ \\
\hline SM-16 & $1,50 \mathrm{a}$ & $2,50 \mathrm{~b}$ & $3,50 \mathrm{~b}$ & $4,00 \mathrm{a}$ \\
\hline Sta Adélia & $1,16 \mathrm{a}$ & $1,83 \mathrm{c}$ & $3,33 \mathrm{~b}$ & $3,83 \mathrm{a}$ \\
\hline Supera F1 & $1,50 \mathrm{a}$ & $2,33 \mathrm{~b}$ & $4,00 \mathrm{a}$ & $4,00 \mathrm{a}$ \\
\hline Hy Color & $1,83 \mathrm{a}$ & $2,50 \mathrm{~b}$ & $4,00 \mathrm{a}$ & $4,16 \mathrm{a}$ \\
\hline \multicolumn{5}{|l|}{ Ambientes } \\
\hline Geladeira & $1,40 \mathrm{a}$ & $2,06 \mathrm{~b}$ & $2,73 \mathrm{~b}$ & $3,06 \mathrm{~b}$ \\
\hline $\mathrm{T}^{\circ} \mathrm{Amb}$ & $1,73 \mathrm{a}$ & $2,86 \mathrm{a}$ & $4,80 \mathrm{a}$ & $5,00 \mathrm{a}$ \\
\hline CV (\%) & 30,83 & 14,80 & 9,69 & 7,84 \\
\hline
\end{tabular}

Médias seguidas de mesma letra nas colunas não diferem entre si pelo teste de Scott-knott a 5\% de probabilidade.

Means followed by the same letter in the column do not differ significantly by Scott-knott with $\mathrm{p}<(0,05)$.

Tabela 5. Sólidos solúveis totais (SST, em graus Brix) de frutos colhidos no ponto verde maduro, frutos amadurecidos na planta e dos frutos colhidos verdes e amadurecidos fora da planta, em temperatura ambiente e geladeira.

Tabela 5. Total soluble solids ( ${ }^{\circ}$ Brix) of tomato fruits harvested at ripe green index, fruits ripened in the vine and of fruits harvested green and ripened outside the plant, at room temperature and in cooling room.

\begin{tabular}{lccc}
\hline & $\begin{array}{c}\text { Frutos } \\
\text { verdes }\end{array}$ & $\begin{array}{c}\text { Frutos maduros } \\
\text { na planta }\end{array}$ & $\begin{array}{c}\text { Frutos maduros } \\
\text { fora da planta }\end{array}$ \\
\hline Cultivares & & & \\
\hline Fascínio & $2,90 \mathrm{a}$ & $4,27 \mathrm{a}$ & $5,35 \mathrm{c}$ \\
SM-16 & $3,03 \mathrm{a}$ & $3,64 \mathrm{~b}$ & $5,50 \mathrm{~b}$ \\
Sta Adélia & $3,00 \mathrm{a}$ & $4,30 \mathrm{a}$ & $5,85 \mathrm{a}$ \\
Supera F1 & $2,53 \mathrm{~b}$ & $3,59 \mathrm{~b}$ & $5,13 \mathrm{~d}$ \\
Hy Color & $3,03 \mathrm{a}$ & $4,21 \mathrm{a}$ & $5,5 \mathrm{~b}$ \\
\hline Ambientes & & & \\
\hline $\mathrm{T}^{\circ}$. Amb. & - & - & $5,55 \mathrm{a}$ \\
Geladeira & - & - & $5,38 \mathrm{~b}$ \\
\hline $\mathrm{CV}(\%)$ & 3,45 & 7,2 & 1,98 \\
\hline
\end{tabular}

Médias seguidas de mesma letra nas colunas não diferem entre si pelo teste de Scott-knott a 5\% de probabilidade.

Means followed by the same letter in the column do not differ significantly by Scott-knott with $\mathrm{p}<(0,05)$.
Os frutos que foram colhidos no estádio verde-maduro e completaram a maturação fora da planta, Santa Adélia destacou-se com as maiores médias, depois as cultivares SM16 e Hy Color, as quais não se diferiram estatisticamente, seguida da Fascínio, e com menores médias ficou a cultivar Supera F1. Com relação aos ambientes, os frutos que amadureceram em temperatura ambiente obtiveram melhores médias de sólidos solúveis totais.

\section{DISCUSSÃO}

As altas temperaturas registradas no período podem ser consideradas como fator limitante, pois médias acima de $27,5^{\circ} \mathrm{C}$ podem reduzir em até $40 \%$ a frutificação (HAREL et al., 2014). As temperaturas ideais para a produção de tomate são de $18^{\circ} \mathrm{C}$ a $24{ }^{\circ} \mathrm{C}$ para a floração $14^{\circ} \mathrm{C}$ a $24^{\circ} \mathrm{C}$ para o pegamento de fruto e $20^{\circ} \mathrm{C}$ a $24^{\circ} \mathrm{C}$ no período da maturação, acima disso pode ocasionar abortamento de flores e frutos, ou coloração de frutos manchado ou com coloração amarelada (Alvarenga, 2013), e durante esse trabalho não foram registrados abortamentos ou maturação irregular, resultado esse que demonstra potencial para produção das cultivares avaliadas em condições do experimento.

Observando os resultados da amplitude térmica diária, percebe-se uma grande variação entre as temperaturas diurnas e noturnas, onde a média de variação foi de $15,7^{\circ} \mathrm{C}$. Variações de temperaturas entre 6 a $7^{\circ} \mathrm{C}$ entre o dia e a noite são consideradas positivas, onde as temperaturas ideais para a cultura estão entre 15 a $20^{\circ} \mathrm{C}$ durante a noite e 21 a $28^{\circ} \mathrm{C}$ durante o dia (FILGUEIRA, 2008).

A cultivar Fascínio apresentou maior produtividade (Tabela 1), obtendo uma produção 74,8 \% acima das demais cultivares e valores superiores aos encontrados por Schwarz et al. (2013), em experimento em campo aberto comparando cultivares de tomate de hábito determinado, que obteve média de produção total para a cultivar fascínio, de 39,6 e $55,1 \mathrm{t} \mathrm{ha}^{-1}$, para primeiro e segundo ano de experimento.

Todas as cultivares avaliadas obtiveram resultados superiores à média nacional, que foi de $70 \mathrm{t} \mathrm{ha}^{-1}$ no ano de 2015 e superiores também aos encontrados por Resende; Costa (2000), que avaliando 10 cultivares de tomate de hábito determinado, obteve médias de produção entre 70,86 a 96,68 t ha ${ }^{-1}$. Os resultados de produção obtidos nesse estudo foram superiores à produtividade média de Mato Grosso $(24,96 \mathrm{t}$ $\mathrm{ha}^{-1}$ ) e nacional (54,5 $\mathrm{t} \mathrm{ha}^{-1}$ ) (AGRIANUAL, 2016).

Não foi realizado desbaste dos frutos, a qual é uma prática bastante usual em produção de tomates visando consumo "in natura", essa prática altera a relação fonte-dreno propiciando aumento no tamanho e massa média dos frutos (ALVARENGA, 2013), e mesmo assim observou-se que apesar da elevada quantidade de frutos por planta, a massa unitária dos frutos não foi prejudicada (Tabela 1). Como os frutos são drenos metabólicos fortes, os fotoassimilados são translocados preferencialmente a estes órgãos (CHARLO et al., 2009; WAMSER et al., 2009; HESAMI et al., 2012).

Os tomates são classificados pelo tamanho que, por sua vez, é medido através da circunferência ou diâmetro transversal (FONTES et al., 2000), largura (AMARAL JÚNIOR et al., 1997), massa e volume (FERREIRA et al., 2000). Os híbridos de hábito determinado avaliados, são do tipo Italiano, que possuem o formato alongado, com 70 a 100 $\mathrm{mm}$ de comprimento e diâmetro transversal reduzido, de 30 a $50 \mathrm{~mm}$ (FILGUEIRA, 2008). 
O pericarpo compreende a casca (epicarpo), e as paredes internas do fruto, denominadas mesocarpo e endocarpo (CEAGESP, 2006). A espessura do pericarpo do tomate é um indicativo de produtividade, visto que frutos com parede mais grossa são mais pesados, e também é um indicativo de qualidade e pós-colheita, pois essa característica está associada a maior firmeza e ficam menos propensos ao murchamento (SHIRAHIGE, 2009).

Os resultados obtidos foram superiores aos encontrados por Schwarz et al. (2013), os quais trabalhando com dez cultivares de tomate de hábito determinado, em dois anos de cultivo no município de Pinhão no Paraná, obtiveram médias de espessura de pericarpo entre 5,0 $\mathrm{mm}$ e $8,3 \mathrm{~mm}$. Essa característica está relacionada com as características genéticas próprias de cada híbrido, ou com a interação com o ambiente no qual está inserido, visto que o autor também trabalhou com as cultivares Supera F1 e Fascínio, com espessura de parede entre 5,2 e 5,5 $\mathrm{mm}$ para Supera e 5,4 e 7,1 $\mathrm{mm}$ para Fascínio, considerando primeiro e segundo ano, sendo que os resultados desses materiais foram bastante inferiores ao presente trabalho.

Assim, ficam evidentes características de dupla aptidão das cultivares testadas, pois, por possuírem parede mais espessa, contribuem também para rendimento de polpa na indústria, além de serem mais resistentes à colheita mecanizada e ao transporte (MELO; VILELA, 2005). A obtenção de tomates com maior potencial de conservação aumenta a tolerância ao manuseio dos frutos, aumenta a vida de prateleira e permite a produção em locais distantes dos centros de consumo (KRAMMES et al., 2003). O tomate é um fruto altamente perecível, e suas perdas na pós-colheita podem chegar a 21\%, devido ao seu alto teor de água (RINALDI et al., 2011), a qual fica entre 90 e $95 \%$, fator esse que torna o fruto bastante sensível (ROCHA et al., 2009).

A maioria dos produtos hortícolas sofrem danos físicos momentos após a colheita, visto que nesse momento ocorrem aumento da respiração, produção de etileno e outras reações bioquímicas responsáveis por mudanças na coloração, textura e qualidade nutricional (MENDES et al., 2011). Por isso a fase de maturação do tomate no momento da colheita, bem como o controle de pré e pós-colheita, são fatores imprescindíveis para garantir a qualidade do fruto (BECKLES, 2012).

No momento da colheita há uma brusca interrupção do suprimento de água da planta para o fruto, e ocorre um aumento na atividade de respiração e transpiração, principalmente no período inicial de armazenamento, sendo que essa é uma das principais causas de perdas no póscolheita (CHITARRA; CHITARRA, 2005).

Após a colheita o tomate passa por processos fisiológicos como o processo de transpiração e maturação, causando desidratação e consequente perda de massa (NETO et al., 2016). Todas as cultivares avaliadas e em ambos os ambientes não apresentaram qualquer sinal de desidratação até os 21 dias após a colheita, sinais esses que só foram aparentes na última semana do experimento em todas as cultivares avaliadas. Considerando esse período de 21 dias de armazenamento que os frutos apresentaram qualidade melhor, não houve diferença estatística entre os ambientes (Tabela 3). O tomate é envolto por uma pele quase impermeável a gases, então suas trocas gasosas podem ser essencialmente restritas a cicatriz peduncular, deixada pela abscisão da corola, ao tempo de formação do fruto (PEDRAS; RODRIGUES, 1983).
A umidade relativa ideal para conservação da maioria das frutas e verduras é entre 90 e $95 \%$ para evitar perdas (KADER, 1992). No presente trabalho as condições de umidade do ar foram distantes das ideais para o armazenamento de frutos, com média de $10 \%$ na geladeira e $70 \%$ no ambiente sem refrigeração. Ao avaliar a perda de massa de tomates 'Santa Clara' e seu mutante firme, armazenados a $27^{\circ} \mathrm{C}$ e umidade relativa de $60 \%$ (condições bastante adversas, e próximas do presente trabalho) por um período de 15 dias, Moura et al. (1999) obtiveram perda de massa de $7 \%$ para a Santa Clara e $4 \%$ para seu mutante firme.

No presente trabalho, a cultivar Fascínio obteve alta durabilidade pós-colheita, 28 dias de armazenamento, apresentando perda de massa menor que as demais cultivares aos 14 dias de armazenamento (Tabela3). Ao comparar os tipos de armazenamento apesar dos frutos armazenados na geladeira apresentarem média de 14 dias de durabilidade póscolheita esse ambiente proporcionou menor perda de massa dos frutos $(7,80 \%)$ ao comparar com os frutos armazenados em temperatura ambiente $(8,77 \%)$ (Tabela 3). Paula et al. (2011), trabalhando com três estádios de maturação em tomate concluíram que frutos colhidos verdes apresentam maior vida pós-colheita e maior resistência ao transporte.

Para evitar a perda de água de frutas e hortaliças no póscolheita é necessário um ambiente de armazenamento com temperatura, umidade relativa e circulação de ar adequados (CHITARRA; CHITARRA, 2005). O tomate é um fruto climatérico, apresentando pico de atividade respiratória no processo de maturação pós-colheita (WILLS et al., 1982). Então a partir desse pico que começa o processo de deterioração, e o fruto começa a mudar sua coloração e a perder a firmeza da polpa, além de ocorrerem diversas mudanças bioquímicas, alterando o sabor, o odor e as qualidades organolépticas (MEDINA; MEDINA, 1981). No período pós-colheita as transformações são mais rápidas à medida que aumenta a temperatura de exposição dos frutos (DOMIS et al., 2001).

As condições ideais de armazenamento refrigerado dependem do tipo de produto e devem favorecer a manutenção do sabor, aroma, firmeza e cor da polpa (CHITARRA; CHITARRA, 2005). A temperatura é um fator determinante para manter a qualidade e a longevidade do fruto na pós-colheita, pois o armazenamento de tomates no ponto verde maduro em temperaturas abaixo de $7^{\circ} \mathrm{C}$ podem causar injúrias no fruto, como coloração desuniforme, manchas na superfície e descoloração interna causada por colapso das células (WILLS et al., 1998). A temperatura ótima de armazenamento depende do estádio de amadurecimento. Tomates no estádio parcialmente maduros devem ser armazenados sob temperatura entre 10 e $12^{\circ} \mathrm{C}$ (BRACKMANN et al., 2007).

O teor de sólidos solúveis totais é responsável pelo sabor agradável dos frutos, e pode ser influenciado por diversos fatores, como estágio de maturação da colheita, temperatura e disponibilidade de água, adubação, característica genética da cultivar e os processos de respiração e transpiração do fruto (GIORDANO et al., 2000). Além de auxiliar na palatabilidade do fruto, os níveis de sólidos solúveis indicam o grau de maturidade ou amadurecimento do mesmo (VIEIRA et al., 2014).

Os resultados dos sólidos solúveis totais dos frutos que completaram a maturação na planta são superiores aos encontrados por Caliman et al. (2003) em tomate cultivado em ambiente protegido, que obtiveram média geral de SST 
de $3,62^{\circ}$ brix avaliando as cultivares $\mathrm{BGH}-320$, Carmen e Santa Clara, no entanto, em campo aberto os autores obtiveram média geral de SST bastante superior, de $5,85^{\circ}$ brix nas cultivares avaliadas. Bertin et al. (2000), sugerem que os frutos produzidos em ambiente protegido apresentam menor teor de sólidos solúveis totais se comparados ao campo aberto, devido a menor atividade fotossintética, resultado da menor luminosidade ou maior acúmulo de água nos frutos, favorecido pela maior umidade relativa do ar encontrado em ambientes protegidos com equipamento para umidificação.

Após a colheita aumentou os sólidos solúveis totais, resultado de atividades biológicas como a conversão de ácidos orgânicos e hidrólise de amido.

Durante o armazenamento e amadurecimento ocorre variação dos sólidos solúveis totais de tomates, e devido à perda de massa dos frutos devido ao processo de transpiração, há um favorecimento no teor de sólidos solúveis totais, isto porque há concentração nos teores de açúcares no interior dos tecidos (KLUGE; MINAMI, 1997).

Comparando os teores de sólidos solúveis totais entre os frutos maduros na planta e os frutos que amadureceram fora da planta, esses últimos apresentaram valores maiores, contrapondo a afirmação de Moura et al. (1999), os quais afirmam que frutos colhidos verdes, e amadurecidos fora da planta apresentam sólidos solúveis totais inferiores aos frutos maduros na planta.

\section{CONCLUSÕES}

A cultivar Fascínio apresentou maiores médias de produtividade por hectare, maior massa de fruto e maior calibre, e menor percentual de perda de massa no pós colheita, sendo a melhor indicada para o cultivo em regiões tropicais.

$\mathrm{O}$ ambiente refrigerado foi o mais eficiente para diminuir a perda de massa no pós-colheita.

As cultivares Santa Adélia, Fascínio e Hy Color destacaram-se com maiores teores de sólidos solúveis totais entre os frutos colhidos no ponto vermelho maduro, e a cultivar Santa Adélia se destacou entre os frutos colhidos no ponto verde maduro.

\section{AGRADECIMENTOS}

À CAPES pela bolsa concedida a primeira autora e à FAPEMAT pelo financiamento do projeto.

\section{REFERÊNCIAS}

ABCSEM_Associação Brasileira de comércio de sementes e mudas. 2014. Tomaticultura-valioso segmento do agronegocio nacional. Disponível em: http://abcsem.com.br/realeases/2420/Tomaticulturavalioso segmento do agronegocio nacional. Acesso em: Setembro de 2017.

AGRIANUAL. Anuário da Agricultura Brasileira. 21 ed. São Paulo: FNP Consultoria e comércio, 2016. 497p. Disponível em: http://agrianual.com.br/. Acesso em janeiro de 2017.

ALVARENGA, M. A. R. Tomate: produção em campo e casa-de-vegetação e hidroponia. Lavras: UFLA, 2013. 392p.

BAZGAOU, A.; FATNASSI, H.; BOUHROUD, R.; GOURDO, L.; EZZAERI, K.; TISKATINE, R.; DEMRATI, H.; WIFAYA, A.; BEKKAOUI, A.;
AHAROUNE, A.; BOUIRDEN, L. An experimental study on the effect of a rock-bed heating system on the microclimate and the crop development under canarian greenhouse. Solar Energy, v. 176, p. 42-50, 2018. DOI: 10.1016/ j.solener.2018.10.027.

BECKLES, D. M. Factors affecting the postharvest soluble solids and sugar content of tomato (Solanum lycopersicum L.) fruit. Postharvest Biology and Technology, Amsterdam, v. 63, n. 1, p. 129-140. 2012. DOI: https://doi.org/10.1016/j.postharvbio.2011.05.016.

BERTIN, N.; GUICHARD, S.; LEONARDI, C.; LONGUENESSE, J. J.; LANGLOIS, D.; NAVEZ, B. Seasonal evolution the quality of fresh glasshouse tomato under Mediterranean conditions, as affected by vapour pressure deficit and plant fruit load. Annals of Botany, London, v. 85 , p. 741-750, 2000. DOI: 10.100/anbo.2000.1123.

BRACKMANN, A.; STEFFENS, C. A.; ANDRIOLO, J. L.; PINTO, J. A. V. Armazenamento de tomate cultivar "Cronus" em função do estádio de maturação e da temperatura. Ciência Rural, Santa Maria, v.37, p12951300, 2007. Disponível em: https://www.scielo.br/j/cr/a/MM6YTdjgBQN6TLwX $\mathrm{nVztKzg} /$ ?format $=\mathrm{pdf \& lang}=\mathrm{pt}$

BRASIL. Ministério da Agricultura, do Abastecimento e da Reforma Agrária: Portaria $\mathbf{n}^{\circ} \mathbf{5 5 3}$ de $\mathbf{3 0}$ de agosto de 1995. Dispõe sobre a norma de identidade, qualidade, acondicionamento e embalagem do tomate in natura, para fins de comercialização e revoga as especificações de identidade, qualidade, acondicionamento e embalagem do tomate, estabelecidas pela Portaria $n^{\circ} .76$, de 25 de fevereiro de 1975. 1995.

CALIMAN; F. R. B.; SILVA, D. J. H.; MARTINS, C. J. L.; MOREIRA, G. R.; STRINGHETA; P. C.; MARIN, B. G. Acidez, 'brix e 'sabor' de frutos de diferentes genótipos de tomateiro produzidos em ambiente protegido e no campo. Horticultura Brasileira, Brasília, 2003. 5p. Disponível em: http://www.abhorticultura.com.br/biblioteca/arquivos /Download/Biblioteca/olfg4152c.pdf

CEAGESP_Centro de Qualidade em Horticultura. Classificação do tomate. São Paulo - ABH. Disponível em: < http://www.ceagesp.gov.br/wpcontent / uploads /2015/07/tomate.pdf >. Acesso em novembro de 2017.

CHARLO, H. C.; SOUZA, S. C.; CASTOLDI, R.; BRAZ, L. Desempenho e qualidade de frutos de tomateiro em cultivo protegido com diferentes números de hastes. Horticultura Brasileira, Brasília, v. 27, p. 144-149, 2009. http://dx.doi.org/10.1590/S0102-05362009000200004.

CHITARRA, M. I. F.; CHITARRA, A. B. Pós-colheita de frutos e hortaliças: fisiologia e manuseio. 2 ed. Lavras: UFLA, 2005. 785p.

DOMIS, M.; PAPADOPOULOS, A. P.; GOSSELIN, A. Greenhouse tomato fruit quality. Horticulture Review, v. 26, p. 239-349, 2002.

FAOSTAT. Área colhida, rendimento e produção nos principais países produtores de tomate. Disponível em: < http://faostat.fao.org/>. Acesso em: 29 ago. 2019.

FILGUEIRA, F. A. R. Novo Manual de Olericultura Agrotecnologia moderna na produção e comercialização de hortaliças. 4 ed. Viçosa: Editora FV, 2013. 421p.

FILGUEIRA, F. A. R. Novo Manual de Olericultura Agrotecnologia moderna na produção e comercialização de hortaliças. 3 ed. Viçosa: Editora UFV, 2008. 421p. 
FONTES, P. C. R.; SILVA, D. J. H. Cultura do tomate. In: FONTES, P. C. R. Olericultura: teoria e prática. Viçosa: Editora UFV, 2005. p. 457-475.

GIORDANO, L. B.; SILVA, J. B. C.; BARBOSA, V. Colheita. In: SILVA, J. B. C. da; GIORDANO, L. de B. (Orgs). Tomate para processamento industrial. Brasília: Embrapa CNPH, 2000. 168p.

HAREL, D.; FADIDA, H.; ALIK, S.; GANTZ, S.; SHILO, $K$. The effect of mean daily temperature and relative humidity on pollen, fruit set and yield of tomato grown in commercial protected cultivation. Agronomy, Basel, v. 4, n. 1, p. 167-177, 2014. DOI: https://doi.org/10.3390/agronomy4010167.

HESAMI, A.; SARIKHANI, S. K.; HOSSEINI, S. S. Effect of shoot pruning and flower thinning on quality and quantity of semi-determinate tomato (Lycopersicon esculentum). Notulae Scientia Biologicae, v. 4, p. 108 111, 2012. DOI: https://doi.org/10.15835/nsb417179.

IBGE_Instituro Brasileiro de Geografia e Estatística. Levantamento sistemático da produção agrícola. Pesquisa mensal de previsão e acompanhamento das safras agrícolas no ano civil. In: Produtos: tomate. p. 77. v. 18, n. 12. Dezembro 2016. Disponível em: https://www.agricultura.rs.gov.br/upload/arquivos/201 904/25164634-lspa-pesquisa-mensal-de-previsao-eacompanhamento-junho-de-2016.pdf. Acesso em: Janeiro de 2018.

KADER, A. A. Selecting a cooling method in: Postharvest technology of horticultural crops. California. University of California, 1992. p. 63-68.

KRAMMES, J. G.; MEGGUER, C. A.; ARGENTA, L. C.; AMARANTE, C. V. T.; GROSSI, D. Uso do 1metilciclopropeno para retardar a maturação de tomate. Horticultura Brasileira, Brasília, v. 21, n. 4, p. 611-614. 2003. DOI: $10.1590 /$ S0102-05362003000400006.

KLUGE, R. A. Efeito de ésteres de sacarose no armazenamento de tomates 'Santa Clara'. Scientia Agrícola, Piracicaba, v. 54, n. 1-2, p. 39-44, 1997. DOI: http://dx.doi.org/10.1590/S0103-90161997000100006.

LI, R.; GAO, S.; FEI, Z.; LING, K. S. Complete genome sequence of a new tobamovirus naturally infecting tomatoes in Mexico. Genome Announcements, v. 1, n. 5, p. e00794-13, 2013. DOI: 10.1128 / genomeA.00794 13.

MARTINS, G. Uso de casa de vegetação com cobertura plástica na tomaticultura de verão. 65p. Tese (Doutorado) - Universidade Estadual Paulista "Júlio de Mesquita Filho", Jaboticabal, 1992.

MATOS, E. S.; SHIRAHIGE, F. H.; MELO, P. C. T. Desempenho de híbridos de tomate de crescimento indeterminado em função de sistemas de condução de plantas. Horticultura Brasileira, v. 30, p. 240-245, 2012. http://dx.doi.org/10.1590/S010205362012000200010.

MEDINA, P. V.; MEDINA, R. M. Descrição bioquímica e fisiológica da maturação dos frutos de tomateiro. Revista Ceres, Viçosa, v. 28, n. 155, p. 1-7, 1981.

MELO, P. C. T.; VILELA, N. J. Desafios e perspectivas para a cadeia brasileira do tomate para processamento industrial. Horticultura Brasileira, v. 23, n. 1, p. 154 157. 2005. DOI: http://dx.doi.org/10.1590/S0102 05362005000100032.

MENDES, T. D. C.; SANTOS, J. S. dos; VIEIRA, L. M.; CARDOSO, D. S. C. P.; FINGER, F. L. Influência do dano físico na fisiologia pós-colheita de folhas de taioba.
Bragantia, Campinas, v. 70, n. 3, p. 682-687, 2011. DOI: 10.1590/S0006-87052011000300026.

MOURA, M. A. de. Crescimento e pós-colheita de frutos do tomateiro cv. Santa Clara e do seu mutante firme. $86 \mathrm{f}$. Tese [Doutorado em Fitotecnia] - Universidade Federal de Viçosa, Viçosa. 1999.

NETO, J. S.; SCHWAN-ESTRADA, K. R. F.; SENA, J. O. A.; JARDINETTI, V. A.; ALENCAR, M. S. R. Qualidade de frutos de tomateiro cultivado em sistema de produção orgânico e tratados com subprodutos de capim limão. Ciência Agronômica, Fortaleza, v. 47, n. 4, p. 633-642, 2016. DOI: http://dx.doi.org/10.5935/18066690.20160076.

NOGUEIRA, S. F.; GREGO, C. R.; QUARTAROLI, C. F.; ANDRADE, R. G.; HOLLER, W. A.; VITAL, D. M. Estimativa de estoque de carbono em sistemas de produção de soja na região norte Mato-Grossense. Campinas: Embrapa Monitoramento por Satélite, 2010. 31p. (Boletim de Pesquisa e Desenvolvimento, 15). Disponível em: https://ainfo.cnptia.embrapa.br/digital/bitstream/item /35146/1/BPD-15.pdf

PAULA, J. T.; GONÇALVEZ, N. B.; RESENDE, F. V.; ALBUQUERQUE, J. O.; PAULA, L. C.; MEERT, L.; RESENDE, J. T. V. Qualidade pós-colheita de frutos de tomateiro orgânico, colhidos em diferentes estádios de maturação. In: CONGRESSO BRASILEIRO DE OLERICULTURA, 51. Anais... Viçosa: ABH, 2011. p. 5182-5189.

RESENDE, G. M.; COSTA, N. D. Produtividade de cultivares de tomate industrial no Vale do São Francisco. Horticultura Brasileira, Brasília, v. 18. n 2, p. 126-129, 2000. DOI: https://doi.org/10.1590/S010205362000000200010

RINALDI, M. M.; SANDRI, D.; OLIVEIRA, B. N.; SALES, R. N.; AMARAL, R. D. A. Avaliação da vida útil e de embalagens para tomate de mesa em diferentes condições de armazenamento. Boletim CEPPA, v. 29, n. 2, p. 305316, 2011.

ROCHA, M. C.; GONÇALVES, L. S. A.; SOARES, A. G.; CARMO, M. G. F. Caracterização física, físico-química e bioquímica de 12 acessos de tomateiro do grupo cereja 989 produzidos sob manejo orgânico. Horticultura brasileira, Brasília, v. 27, n. 2, p. 2899-2906, 2009. DOI: http://dx.doi.org/10.1590/S0034737X2012000400011.

SCHWARZ, K.; RESENDE, J. T. V.; PRECZENHAK, A. P.; PAULA, J. T.; FARIA, M. V.; DIAS, D. M. Desempenho agronômico e qualidade físico-química de híbridos de tomateiro em cultivo rasteiro. Horticultura Brasileira, Brasília, v. 31, n.3, p. 410-418, 2013. DOI: http://dx.doi.org/10.1590/S0102-05362013000300011.

SELEGUINI, A.; SENO, S.; JÚNIOR, M. J. de A. F. Híbridos de tomateiro industrial cultivados em ambiente protegido e campo aberto. Científica, Jaboticabal, v. 35, n. $1, \quad$ p. $80-87, \quad 2007$. DOI: http://dx.doi.org/10.15361/1984-5529.2 007v3 $5 \mathrm{n} 1 \mathrm{p} 80+-+87$.

SHIRAHIGE, F. H. Produtividade e qualidade de híbridos de tomate (Solanum lycopersicum L.) dos segmentos Santa Cruz e Italiano em função do raleio de frutos, em ambiente protegido. 80p. Dissertação [Mestrado em Fitotecnia] - Escola Superior de Agricultura Luiz de Queiroz, Universidade de São Paulo, Piracicaba, 2009. 
SILVA, D. J. H. da; VALE, F. X. R do. Tomate-Tecnologia de produção. Viçosa: Editora UFV, 2007. 237p.

SILVA, F. de A. S.; AZEVEDO, C. A. V. de. Versão do programa computacional Assistat para o Sistema operacional Windows. Revista Brasileira de Produtos Agroindustriais, Campina Grande, v. 4, n. 1, p. 71-78, 2002.

STEFFENS, C. A.; BRACKMANN, A.; PINTO, J. A. V.; EISERMANN, A. C. Taxa respiratória de frutas de clima temperado. Pesquisa Agropecuária Brasileira, Brasília, v. 42, n. 3, p. 313-321, 2007.

VASCONCELOS, M. A. D. S.; MELO FILHO, A. B. de. Conservação de alimentos. Recife: EDUFRPE, 2010. 130p. (Caderno Temático, ETEC-Brasil). Disponível em: http://proedu.rnp.br/handle/123456789/316

VIEIRA, D. A. D. P.; CARDOSO, K. C. R.; DOURADO, K. K. F.; CALIARI, M.; SOARES JÚNIOR, M. S. Qualidade física e química de mini-tomates Sweet Grape produzidos em cultivo orgânico e convencional. Revista Verde de Agroecologia e Desenvolvimento Sustentável, Pombal, v. 9, n. 3, p. 100-108, 2014.

WAMSER, A. F.; BECKER, W. F.; SANTOS, J. P.; MUELLER, S. Influência do sistema de condução do tomateiro sobre a incidência de doenças e insetos-praga. Horticultura Brasileira, v. 26, p. 180-185, 2008. DOI: http://dx.doi.org/10.1590/S010205362008000200010.

WILLS, R.; BURGOS GONZÁLEZ, J. Introducción a la fisiología y manipulación poscosecha de frutas, hortalizas y plantas ornamentales. 2 ed. Zaragoza: Editorial Acribia, 1998. 260p.

WILLS, R. H. H.; LEE, T. H.; GRAHAM, D.; MC GLASSON, W. B.; HALL, E. G. Postharvest: an introduction to the physiology and handling of fruit and vegetables. 2 ed. Kensington: New South Wales University Press Limited, 1982. 161p. 